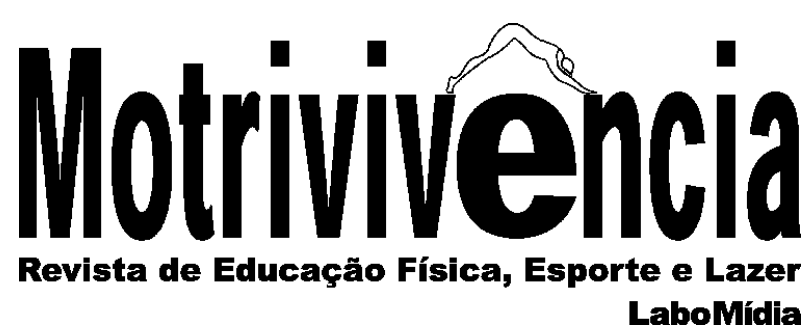

\title{
Caminhos do espírito samurai no karatê shotokan
}

\section{RESUMO}

O ensaio propõe reflexões sobre as estratégias usadas por Funakoshi para modernizar o karatê na era Meiji. Os resultados mostram que, ao deslocar o sentido da prática do karatê para ajustá-lo aos valores ocidentais, o Mestre abdicou do sentido tradicional do budo para investir numa via de formação onde a morte simbólica emerge como prioridade. Isso contribuiu para acelerar a desconstrução da imagem do samurai real e do bushido na modernidade. Funakoshi garantiu a sobrevivência da arte marcial, mas abriu caminhos para a emergência de éticas mitigadas e práticas não convencionais no karatê.

PALAVRAS-CHAVE: Artes marciais; Lutas; Ética.
Milton de Souza Coelho Doutor em Educação Física - UGF Universidade Federal do Rio de Janeiro, Escola de Educação Física e Desportos, Rio de Janeiro, Brasil miltsc@gmail.com D.https://orcid.org/0000-0002-5165-5096

Paulo Renato Moreira da Silva Coelho Especialista em Educação Física Escolar - UCAM Universidade Federal do Rio de Janeiro, Escola de Educação

Física e Desportos, Rio de Janeiro, Brasil prmsc@gmail.com

D. https://orcid.org/0000-0002-3469-4499

Leandro Nogueira Salgado Filho

Doutor em Educação Física - UGF

Universidade Federal do Rio de Janeiro, Escola de Educação

Física e Desportos, Rio de Janeiro, Brasil lnsf@gmail.com

Dhttps://orcid.org/0000-0002-5165-5096

Felipe Triani

Mestre em Humanidades, Culturas e Artes - UNIGRANRIO Universidade do Estado do Rio de Janeiro, Programa de PósGraduação em Ciências do Exercício e do Esporte, Rio de Janeiro, Brasil

felipetriani@gmail.com D.https://orcid.org/0000-0001-6470-8823

Jorge Felipe Columá

Doutor em Educação Física - UGF Centro Universitário Augusto Motta, Curso de Educação

Física, Rio de Janeiro, Brasil

Jorge.columa@gmail.com

D.https://orcid.org/0000-0001-8105-2299 


\title{
Pathways of the spirit samurai in karatê shotokan
}

\begin{abstract}
The essay proposes reflections on the strategies used by Funakoshi to modernize karate in the Meiji era. The results show that by shifting the sense of karate practice to adjust it to Western values, the Master abdicated the traditional sense of budo to invest in a path of formation where symbolic death emerges as a priority. This contributed to accelerate the deconstruction of the image of the royal samurai and bushido in modernity. Funakoshi guaranteed the survival of the martial art, but opened the way for the emergence of mitigated ethics and unconventional practices in karate.
\end{abstract}

KEYWORDS: Martial arts; Fights; Ethic

\section{Caminos del espíritu samurai en el karaté shotokan}

\section{RESUMEN}

El ensayo propone reflexiones sobre las estrategias utilizadas por Funakoshi para modernizar el karate en la era Meiji. Los resultados muestran que, al desplazar el sentido de la práctica del karate para ajustarlo a los valores occidentales, el Maestro abdicó del sentido tradicional del budo para invertir en una vía de formación donde la muerte simbólica emerge como prioridad. Esto contribuyó a acelerar la deconstrucción de la imagen del samurai real y del bushido en la modernidad. Funakoshi aseguró la supervivencia del arte marcial, pero abrió caminos para la emergencia de éticas mitigadas y prácticas no convencionales en el karate.

PALABRAS-CLAVE: Artes marciales; Luchas; Ética 


\section{INTRODUÇÃO}

O presente estudo analisa como, a partir da era Meiji (1868), sob a égide da desportivização $^{1}$, o karatê shotokan como parte integrante das artes marciais japonesas, se reconfigurou para adaptar-se aos ditames do processo de modernização do Japão. Priorizamos a compreensão das estratégias construídas por Funakoshi para fazer a simbiose entre o Japão antigo e o novo sem perder de vista o código de ética do samurai (Bushido) que é a essência do karatê (YUZAN, 2003).

Tendo como pano de fundo o que já fizera seu contemporâneo Jigoro Kano mentor do Caminho da suavidade (Judô), Funakoshi construiu o Caminho das mãos vazias no Karatê (Karatê do). Tal ideia não era de todo original já que na era medieval (Xogunato) o budo já indicava esse tipo de organização da prática para as artes marciais japonesas (RATTI, 2006).

Sabemos que "o novo não está no que é dito, mas no acontecimento à sua volta" (FOUCAULT, 1996, p. 26). Podemos dizer, então, que, ao adjetivar o termo karatê com o designativo "Do", Funakoshi, sob influência de outros grupos de mestres (FUNAKOSHI, 2000), ressemantizou a prática dessa atividade, alterando profundamente a maneira de formar o artista marcial. Além disso, ao aliar a polissemia do termo à cultura da desportivização, Funakoshi agregou, mesmo que sem querer, valores e crenças típicas do imaginário ocidental (FERREIRA, 2003) como, por exemplo, o fair-play, conceito basilar que, de forma intestina, molda e regula as ações na prática dos desportos modernos ocidentais.

Significa dizer que Eros, primando pela vida, referência básica dos desportos ocidentais, passou a competir com Thanatos, instinto de morte, referência inconteste das artes marciais, alterando definitivamente a prática do karatê a partir de então. Nesse viés, o autocontrole, que antes era um atributo voltado para a melhoria da proficiência técnica para ceifar vidas, transforma-se no desejo de regulação, de contenção e de preservação da vida do outro (COELHO et al., 2016) .

O escopo da técnica sai de uma conformação endógena na qual o que importa é o desempenho técnico, para produzir dano ao corpo do outro, para uma configuração exógena, em que a técnica, definitivamente, descola-se da ideia de dolo intencional para dolo eventual. O dolo

\footnotetext{
${ }^{1} \mathrm{O}$ termo desportivização é usado aqui numa perspectiva tradicional onde a escola incorpora o modelo olímpico para se adequar ao processo de modernização do Japão. Sendo assim, esse modelo ocidental impregna as práticas com valores, crenças e atitudes do desporto de competição, favorecendo a ocidentalização, algo bem visto pelos dirigentes japoneses à época. Vale registrar que a convivência de Funakoshi com Jigoro Kano, que já usava tal modelo, ajudou a sedimentar a prática do karatê nesses moldes. Embora ambos fossem educadores do ensino oficial, não havia espaço para uma leitura crítica da prática das artes marcais naquela época, à exemplo do que faz Vago (1996), Valter Bracht (2005) entre outros, na atualidade.
} 
intencional, por princípio, era inerente ao budo ${ }^{2}$ e tinha como referência Thanatos. Na prática, tal perspectiva ética colocava sempre a morte real como desfecho "natural" da maioria dos combates (COELHO et al., 2016).

Segundo Massimi (2006), Funakoshi entra em conflito com a ideia de kime ${ }^{3}$ porquanto este se configura como a alma do gesto técnico do verdadeiro karatê. O Mestre e seus seguidores, premidos pela força da desportivização, investem na ideia de contenção (Sun dome) algo que, embora já existisse desde a era do xogunato, na versão do autor ganha outro sentido: interromper a técnica imediatamente antes de se estabelecer contato com o alvo visando à preservação da integridade física do outro. Mas essa estratégia entrava em conflito com a ideia ikken hissatsu ${ }^{4}$, que pairava como pano de fundo no imaginário do karatê shotokan de Funakoshi e que teria inspirado a criação do Kihon.

Consta que Kihon teria sido criado pelo mestre para desenvolver o sentimento do ikken hissatsu, que, aliado ao uso do makiwara ${ }^{5}$, potencializa o uso da força no punho na hora do impacto (BARREIRA; MASSIMI, 2006). O uso desse aparato mantém vivo o valor simbólico do ikken hissatsu, ao mesmo tempo em que fortalece a crença de que a prática com makiwara fortalece a alma do karatê.

Assim, ao romper com o budo tradicional, Funakoshi, sob influência do contexto em que estava inserido, desloca Thanatos para a dimensão simbólica, eufemiza a noção de morte real e elege, de forma definitiva, Eros como princípio inspirador do karatê desportivizado, abrindo novas perspectivas ético-estéticas e didático-pedagógicas para essa prática (YUZAN, 2003; RATTI, 2006; SAKURAI, 2007).

Nesse novo enfoque, a estética assume o papel de mediador (EAGLETON, 1993) com a função de, através do gesto técnico, construir outros caminhos para a corporalidade. Esse termo é aqui entendido como a experiência capaz de "fazer o movimento [deslocar-se] de uma perspectiva naturalizada baseada apenas na dimensão motriz, para outra, que lhe reconhece o estatuto cultural”. Nesse viés, a corporalidade remete "a expressão criativa e consciente do conjunto das manifestações corporais historicamente produzidas, às quais pretendem possibilitar a comunicação e a interação de diferentes indivíduos com eles mesmos, com os outros, com o seu meio social e natural" (OLIVEIRA; OLIVEIRA; VAZ 2008, p. 306).

O gesto repetitivo transcende os limites da pura execução proficiente para configurar-se como base da estética da sensibilidade (Techné). Além disso, o gesto desenvolve também o controle

\footnotetext{
${ }^{2}$ Budo - código de conduta da era Tokugawa (RATTI, 2006).

${ }^{3}$ Kime - direcionamento da máxima potência do golpe com foco num objetivo. Trad. Livre.

${ }^{4}$ ikken hissatsu - matar ou parar o oponente com um único golpe (BARREIRA; MASSIMI, 2006).

${ }^{5}$ Makiwara - peça usada para golpear e fortalecer o punho (NAKAYAMA apud BARREIRA MASSIMI, 2006).
} 
das emoções na relação com o outro. Na dimensão axiológica, atributos como honra, humildade, polidez, que já eram predicados do samurai na era Tokugawa, reconfiguram-se como marcas distintivas do bom praticante probo, reto, e passa a ter a obrigação de preservar a integridade física do outro, migrando, "naturalmente", para o perfil do cidadão, moderno, objeto de reflexão da arte marcial de cunho educacional.

O deslocamento de sentido da prática do karatê, anunciado por Funakoshi no início da era Meiji no Japão (1868) e concretizado no final do século XX, reduz a ênfase sobre a potência do golpe em favor da velocidade de execução do gesto técnico/contenção.

O perfil do praticante deixa de ser o daquele que executa o golpe potente, ikken hissatsu, e passa a ser o daquele que, mesmo sendo forte, preserva o oponente. Esse foi o grande legado de Funakoshi que, ao construir a sua versão da arte marcial karatê, soube ligar o karatê ao imaginário das artes marciais medievais, preservando traços importantes da figura do samurai e de sua ética (bushido), sem perder o horizonte das potencialidades educativas dessa prática.

A partir de então, tornou-se consensual, no âmbito das artes marciais japonesas, a ideia de que os caminhos de formação transcendem a esfera do estritamente técnico, ou do combate. O karatê desportivizado como subproduto dessa visão, incorpora, então, atributos do samurai medieval cuja práxis não só prioriza ideias como honra, lealdade, respeito à hierarquia, culto aos antepassados, mas também aponta para a ligação do praticante com seu meio circunjacente. Ratti (2006), ao referir-se à doutrina marcial bujutsu ${ }^{6}$ (Era Edo, 1603/1867) observa que,

Sem exceção, quase todos os mestres de artes marciais de maior reputação que escreveram ou ensinaram suas especializações, afirmam que o bujutsu foi (e ainda é) algo a mais do que uma simples variedade de métodos de combate práticos e eficazes. Indicam que estas artes são "meios" ou disciplinas de desenvolvimento moral idealizados para aprofundar a formação de uma personalidade madura, equilibrada e integrada de um homem em paz consigo e em harmonia com seu ambiente social e natural (p. 476).

Ao priorizar a exploração das dimensões pedagógicas do Karatê, Funakoshi inovou e construiu uma interpretação particular dessa arte marcial; algo tão singular que não só foi reconhecido pelos governantes da era pós-Meiji, como também foi incorporada à educação física japonesa no início do século XX (1913), à exemplo do que já fizera Jigoro Kano cuja perspicácia possibilitou a criação do judô (1882) a partir do ju jutsu da era Tokugawa ou Edo (1603-1867) ${ }^{7}$.

\footnotetext{
${ }^{6}$ Bujutsu - Campo de estudo que engloba as diversas armas, técnicas, estratégias, controle interior e poder. Estudo das principais especializações da experiência marcial, conhecidas no Japão feudal como artes marciais ou bujutsu (RATTI, 2006).

${ }^{7}$ Com esse feito Jigoro Kano não só viabilizou uma forma original de formação educacional através do judô,como possibilitou sua inscrição na esfera dos esportes olímpicos, pavimentando a estrada para Funakoshi.
} 
Trata-se de algo relevante porque esse movimento significou deslocamentos de sentidos do karatê shotokan e alterações do modo de lidar com a imagem do samurai. Além disso, simboliza o momento em que, no karatê, viabilizou-se a perpetuação da imagem do samurai e do bushido como ferramentas pedagógicas efetivas para a formação do cidadão.

\section{EUFEMIZAÇÃO DO SENTIDO DE MORTE NO KARATÊ SHOTOKAN}

O projeto de Funakoshi visava sedimentar a ideia de transformação da arte marcial karatê em caminho de formação nos moldes do que exigia o projeto de modernização da restauração Meiji (1868). Tal escopo exigiu do Mestre grande empenho e criatividade para construir uma vertente que atendesse não só aos ditames do novo projeto social, mas, sobretudo, que preservasse características fundamentais da arte marcial. Sabia ele que as artes marciais, de modo geral, por uma questão histórico-cultural, ainda se orientavam pelo "espírito"8 do budô, que, em essência, contemporizava com a possibilidade de morte real (ikken hissatsu).

Vale registrar que na era Tojugawa (1603-1867) o Budô com base no Bujutsu (a luta em si com foco no real), e no Bugei (uso da arte para operar o aperfeiçoamento espiritual), significava o caminho das artes marciais japonesas. De modo geral, o termo descrevia um estilo de vida dos samurais que treinavam tendo a morte real como horizonte. Nesse viés, a prática primava pela proficiência técnica, além de valorizar dimensões éticas, estéticas e filosóficas.

Com a pacificação as idéias de guerra e morte real perderam consistência no budô. Em consequência, ocorreu um deslocamento de sentido nessa prática. Assim, o Bujutsu perdeu consistência diante do Bugei. Significa assinalar que a prática em si com foco no real, tendo a morte como horizonte (Bujutsu) perdeu espaço para o uso da arte marcial como ferramenta para operar o aperfeiçoamento espiritual (Bugei). Em paralelo angariou maior consistência nesse processo o Bushido (código de conduta dos samurais). Nesse viés, ocorreu uma sobrevalorização do Bushido que foi alçado à condição de substância da prática - o caminho da ascese intramundana (iluminação).

No período de modernização do Japão (1868) esse deslocamento de sentido (ORLANDI, 1993) já estava tão disseminado que do Budo real só restava o Bushido ressemantizado onde a luta real, desloca-se para o âmbito interno.

A ascesse intramundana torna-se a fonte de inspiração da prática. $\mathrm{O}$ inimigo sai da dimensão externa, real, para a dimensão interna, abstrata. Daí em diante a luta interior "contra as

\footnotetext{
8 “Espírito" aqui é usado no viés weberiano; tem, portanto, o sentido de cultura (WEBER, 2004).
} 
manifestações egóicas", torna-se a inspiração-mor do artista marcial e marca distintiva do praticante que ao incorporar tais preceitos tende a superar a dimensão de simples "lutador".

Precisava, portanto, romper com o passado, mas não podia apagá-lo totalmente; intuitivamente sabia que o passado daria estofo ao presente. A propósito, Orlandi (1993) apoiada em Pecheux, reflete sobre a importância do passado:

Não há ritual sem falhas (...) Por isso é possível à ruptura. Instauração de uma nova ordem de sentidos. O que o caracteriza como fundador - em qualquer caso, mas precipuamente neste - é que ele cria uma nova tradição, ele re-significa o que veio antes e instituiu aí uma memória outra. É um momento de significação importante, diferenciado. O sentido anterior é desautorizado. Instala-se outra tradição de sentidos que produz os outros sentidos nesse lugar. Instala-se uma nova filiação. Esse dizer irrompe no processo significativo de tal modo que pelo seu próprio surgir produz sua memória (p. 13).

A antiga prática precisava ser superada (não eliminada!) para atender aos anseios da sociedade moderna que surgia. As ligações rizomática mantidas com a antiga prática, quais sejam, budo, Kata, arte de combate, precisavam ser eufemizadas. A nova prática, paulatinamente deveria desautorizar sentidos da prática anterior, legitimando sentidos outros, mais adequados aos novos referenciais do Japão Moderno. Tornava-se crucial a instauração de uma nova ordem de sentidos; o binômio violência/autocontrole precisava ser ressemantizado.

Os fragmentos recolhidos do ritual anterior deveriam servir de base para a emergência de uma ordem outra de sentidos. Nesse viés, o já-dito funcionaria como uma ponte, pois ele "sustenta o sentido que surge e se sustenta nele" (ORLANDI, 1993, p. 13).

Ao adjetivar sua síntese de karatê com o designativo "Do", no início do século XX, Funakoshi lançou a semente de um deslocamento semântico que afetaria profundamente o sentido da prática da arte marcial karatê shotokan nos anos subsequentes. Não queremos dizer, com isso, que foi algo premeditado, mas sim fruto das condições concretas e objetivas a que estava submetido. O estilo de karatê construído por Funakoshi deriva de seu estilo de vida, de seu modo de interagir com o mundo, de seu modo de conceber o processo de formação humana (FUNAKOSHI, 2000).

Como resultado desse processo singular de interação com a cultura marcial japonesa, o caminho das mãos vazias - que a exemplo de outras artes marciais desportivizadas - baseia-se no princípio de eufemização da força de Thanatos (morte). À medida que assume maior compromisso com esse viés, distancia-se da versão tradicional de karatê baseado na ótica do bujutsu e na objetivação da morte (COELHO et al., 2016). 
Simbolicamente, Funakoshi opera o primeiro e mais significativo deslocamento de sentido da ética do bushido (caminho do samurai), na medida em que, decididamente, empurra Thanatos para fora do mundo real, banindo da prática a possibilidade de morte real por efeito de golpes (COELHO et al., 2016).

Ao mesmo tempo em que cria a morte simbólica, Funakoshi, dialogando com os referenciais da desportivização, institui o primado de Eros, simbolizado pela interdição dos golpes mortais, que passam a ser prerrogativa apenas dos faixas pretas severamente controlados pelas federações.

Trata-se de um deslocamento de sentido acentuado, já que a força sígnica de Eros construída e sedimentada na esfera do desporto ocidental institui uma verdade outra na organização da prática do karatê. Eros opõe-se a Thanatos, configurando outro Do (caminho) para o karatê; o sentido da prática desloca-se para a dimensão simbólica, com foco na preservação da integridade física, no autocontrole, na melhoria da qualidade de vida e na preservação da vida.

A estratégia desse discurso, originário da era Meiji, era a de criar um cisma entre a imagem real do samurai e a sua construção simbólica, algo já realizado em parte pelos governantes da era Meiji (1868) que objetivavam deslocar a imagem do samurai da dimensão denotativa para a conotativa, criando um universo outro, capaz de permitir uma profunda reconfiguração semântica.

O discurso oficial, que subliminarmente operava no fazer de Funakoshi, produzia um efeito de identificação natural, automática, entre a figura desse samurai idealizado, ícone da Era Meiji (SAKURAI, 2007), e a prática desportivizada do karatê. A monofonia, a padronização, a dominância do pressuposto sobre o posto marcavam o ritmo de construção dos sentidos e a abrangência desse discurso. Nele sobressai uma tendência a privilegiar certos ritos e rituais e certo uso da dimensão denotativa.

Na prática, o que ocorre é um forte investimento no discurso oficial num viés do designativo samurai, redundando na priorização de uma dimensão em detrimento de outra; isso provoca um efeito de quase apagamento de outros sentidos contidos nessa imagem mítica. Essa mudança de foco desloca o sentido da dimensão literal, denotativa, para a dimensão não literal, simbólica, subjetiva, o que gera o rompimento com a ideia de identificação imediata com o samurai real, concreto, visceralmente ligado ao budo e a Thanatos (morte). Essa outra possibilidade de nomeação remete o designativo samurai à esfera do simbólico, e a prática à esfera da eufemização da morte.

A figura do samurai sofre um deslocamento de sentido no momento da sua reapropriação o que altera, definitivamente, sua forma de veiculação e significação. Daí a necessidade de se trabalhar não com as "evidências", mas com o processo de produção desse conceito, já que o contexto e a relação com o sujeito passam a ser determinantes. Significa dizer que, em última instância, a noção de dado é, ela própria, um efeito ideológico. 
Para fins deste estudo, a Análise do Discurso (AD) procura desconstruir a evidência de tal efeito, explicitando seus modos de produção. "Para tal (...) é a própria noção de real e a de interpretação que são colocadas em questão" (ORLANDI, 1993, p. 9).

O discurso divergente da ótica tradicional construído por Funakoshi apenas refletiu as contradições típicas dos dirigentes da Era Meiji para lidar com a imagem do samurai. Isso contribuiu para a transformação dessa figura controvertida, já que o Mestre teve de adaptar os referenciais identitários tradicionais ao novo contexto. Ocorre nesse caso, uma reconstrução por outras vias da figura do samurai, uma vez que essa nova imagem, inserida no imaginário popular japonês desloca o samurai do campo de batalha para o seio da sociedade, transformando a arte marcial num "meio", e transformando a servidão voluntária, marca distintiva do samurai da Era do Xogunato, num valor a ser seguido e preservado (COELHO et al., 2016b).

Este movimento faz parte de um discurso que culmina com a transformação da figura do samurai e de sua ética em símbolos da cultura japonesa na modernidade. Constrói-se assim, um discurso que, silenciosamente, desautoriza certos sentidos eleitos pelo discurso anterior para marcar e fincar as bases da imagem do "novo" samurai. Significa apagar certos sentidos do budo e da prática corrente do samurai sem, contudo, destruir totalmente a sua imagem, venerada pelo povo. $\mathrm{O}$ funcionamento desse discurso sugere uma aproximação da ideia de implícito sugerida por Ducrot (1972) quando afirma que

o problema geral do implícito, tal como foi apresentado (...) é saber como se pode dizer alguma coisa sem, contudo aceitar a responsabilidade de tê-la dito, o que, com outras palavras significa beneficiar-se da eficácia da fala e da inocência do silêncio (p. 20).

Nessa perspectiva, a nova imagem do samurai e sua ética funcionando como referenciais de conduta dos praticantes de karatê legitimam sentidos que passam a marcar a identidade do praticante de karatê na atualidade. A propósito, vale registrar que a introdução de novas técnicas e formas de treinamento, por exemplo, são decorrentes da reinterpretação da figura do samurai e de seu código de ética, o bushido (COELHO et al., 2016).

Isso aconteceu com o filho de Funakoshi, Yoshitaka (Gigo), que, sob a égide de uma imagem reconfigurada do samurai que exigia novas técnicas e formas de treinamento diferenciado, e visando a dar mais ênfase à prática do combate, sedimentou, no karatê, o Kihon Ippon Kumite (1932) e instruiu a prática do Jiyu Kumite ("kumite livre") além incorporar bases mais baixas que as tradicionais e técnicas de pernas, como o Yoko Geri (Kekomi e Keage) (1935) (BARREIRA; MASSIMI, 2006; FROSI; MAZO, 2011). 
Fica subentendido, portanto, que o modo de conceber a imagem do samurai e sua ética implica novas formas de interagir com a prática e com os valores nela contidos.

Essa forma de ver o objeto que desmistifica ${ }^{9}$ a ideia de literalidade e transparência de leitura, coloca a polissemia como fator estratégico no processo de compreensão dos sentidos da prática e assegura a relativa autonomia do sujeito enquanto criador, enquanto partícipe da invenção do seu cotidiano. Numa inversão de perspectiva

desloca a atenção do consumo supostamente passivo dos produtos recebidos para a criação anônima, nascida da prática do desvio no uso desses produtos (...) é preciso interessar-se não pelos produtos culturais oferecidos no mercado dos bens, mas pelas operações dos seus usuários; é senhor ocupar-se com as maneiras diferentes de marcar socialmente o desvio operado num dado por uma prática (CERTEAU, 1994, p. 13).

Nessa conjuntura, os "sentidos" deslizam, ou se deslocam de acordo com a tensão exercida pelo discurso hegemônico que, ao negociar com cada contexto, faz concessões às suas exigências visando atender às suas peculiaridades. A imagem do samurai se desloca, então, para a dimensão de metáfora na Era Edo (1603-1868), para ícone na era Meiji (1868), e para símbolo na atualidade.

Isso provoca uma "identificação quase natural” dos praticantes com essa figura que, associada à imagem do Mestre, torna-se, por excelência, o modelo exemplar, já que, em sua conduta, articula crenças, atitudes e valores legitimados, sobretudo, pelo seu modo de agir e de conceber a ética do bushido na esfera do karatê desportivizado (COELHO et al., 2016a).

Nesse novo contexto, onde a fragmentação tende a inspirar novas práticas e o neotribalismo ${ }^{10}$ assume lugar de destaque (MAFFESOLI, 2006), ocorrem mudanças em função da reapropriação da prática do karatê que condicionam deslocamentos de sentidos do bushido.

Ganha relevo nesse quadro a questão da reinterpretação de dois quesitos fundamentais para balisar a prática do karatê. Trata-se dos conceitos kime e Sun-dome (BARREIRA; MASSIMI, 2006). O primeiro significa "espírito impelido", força do golpe, direcionamento da máxima potência do golpe com foco num objetivo (tradução livre), já o segundo, denota interromper a execução da técnica. Da oposição entre os dois deriva o conceito de autocontrole (BARREIRA; MASSIMI, 2006).

\footnotetext{
${ }^{9}$ Desmistificar significa ao pé da letra desfazer a mistificação de; ou denunciar equívocos. A Análise de Discurso (AD) porém, quer mais; ela sustenta-se na ideia de que o sentido sempre pode ser outro (PECHEUX,1988). AD com base na ideologia abandona os estudos de cunho lexicológicos sobre o modus operandi da linguagem e volta-se para o questionamento da ideia de verdade absoluta contida na literalidade (PECHEUX, 1988).

${ }^{10} \mathrm{O}$ termo neotribalismo aqui é utilizado para nomear os novos grupos de praticantes de artes marciais que, de certo modo, atuam nos moldes do que preceitua Maffesoli (2006).
} 
Sob a égide de Eros, essa oposição reconfigura-se e produz uma nova ideia de zanshin (espírito de luta), na qual, paradoxalmente, a integridade física do outro não pode ser ferida. Nesse viés, o karatê de Funakoshi afasta o praticante da ideia de combate real, deixando de seguir a orientação do ikken hissatsu (matar com um só golpe). Ocorre uma perda substancial da catarse, da canalização da energia para o golpe já que a representação do poder de impacto máximo do lutador fica alterada em função de uma concepção que não admite mais a ideia de uso do limiar máximo de impacto num único golpe (BARREIRA; MASSIMI, 2006).

Nesse caso, a orientação do treinamento das técnicas desloca-se de uma dimensão endógena para uma dimensão exógena; significa dizer que a configuração movigênica, que antes estava atrelada ao uso da proficiência técnica para a produção do maior potencial de impacto possível, deixa de fazer sentido em favor da preservação do corpo do outro.

Eros, referência básica do karatê desportivizado, ao renegar Thanatos, marca do karatê tradicional, deixa em agonia o Budo, fonte primordial de sentidos das artes marciais da era medievais (xogunato) (COELHO et al., 2016a).

Tal mudança exigirá um reposicionamento da imagem do samurai enquanto fonte de sentidos e, consequentemente, determinará uma reorganização da prática e dos sentidos ligados a essa prática.

Conforme Elias (1939), o autocontrole, por exemplo, necessariamente precisará deslocar-se para a dimensão exógena; já não basta uma boa execução da técnica, torna-se vital que não seja letal. O autocontrole deixa de ser a forma que permite canalizar toda a força e energia para a letalidade de um único golpe (proficiência técnica), para transformar-se, paradoxalmente, no freio, (controle das emoções), impedindo a emergência de Thanatos como o triunfo da concretização de uma técnica bem executada (ikken hissatsu).

\section{CONSIDERAÇÕES FINAIS}

O modo como Funakoshi explora a figura do samurai e de sua ética tende a privilegiar a dimensão conotativa, o que implica a perda de sentido de sua letalidade, obviamente cabe ressaltar a influência do contexto social e histórico em que estava inserido. Essa reapropriação interfere na reconfiguração do bushido (Bushi = Guerreiro; Do = caminho; Caminho do guerreiro), favorecendo a emergência de éticas mitigadas e a diversificação das práticas e dos processos de formação. 
Funakoshi acentua um deslocamento de sentido que já estava em marcha desde o final do século XIX (Restauração Meiji, 1868) quando a figura real do samurai como guerreiro especializado no uso do bujutsu perde espaço para o samurai idealizado pela ética do bushido.

Essa reconfiguração da imagem do samurai que enfraquece a ideia de uso da letalidade do jutsu (técnica) em favor dos atributos que lhe são inerentes, probidade, lealdade, arrrojo, humildade entre outros, contribuem para tornar a arte marcial um meio e não mais um fim.

Vivendo o dilema de manter a tradição do bushido sem perder de vista os pressupostos da emergente desportivização, Funakoshi redefine os desígnios do karatê shotokan, deslocando a ideia de combate "real" para o campo simbólico, conferindo ao ikken hissatsu uma dimensão puramente alegórica. O sentido da prática desliza, portanto, da dimensão endógena ${ }^{11}$ para a dimensão exógena ${ }^{12}$.

Significa dizer que Funakoshi, ao investir na primazia do caráter pedagógico do karatê, redefiniu seu significado caracterizando-o como uma "Tradição inventada (...) prática, de natureza ritual ou simbólica, [que] visa inculcar certos valores e normas de comportamento através da repetição, o que implica automaticamente, uma continuidade em relação ao passado" (HOBSBAWM; TERENCE, 2008, p. 9).

Com esse escopo, o karatê de Funakoshi projeta, para o Japão e para o mundo, uma imagem dúbia do samurai, da qual sobressaem atributos em que ora a belicosidade é exaltada, como por exemplo na guerra Russo-Japonesa (1904-1905) (DEZEM, 2005, p. 258), ora é sutilmente ocultada em favor de uma "virtude de pura forma, de etiqueta, virtude do aparato" (...) "imagem mistificada vendida como ideal de vida" (DHOQUOIS,1993, p. 15).

A partir dessa perspectiva dúbia, a pedagogia do bushido, no plano real, descola-se do bujutsu $^{13}$ e, no plano simbólico, consolida-se como preservadora estratégica do Yamato Damashi ${ }^{14}$, sobretudo durante a modernização do Japão. Sakurai (2007), sobre esse aspecto, observa que

\begin{abstract}
Nas aulas e nos barracões militares, ensinava- se ao jovem japonês a glorificar as tradições militares do Japão. Eles chegavam a acreditar que a morte no campo de batalha pelo imperador era o destino mais glorioso do homem e nas virtudes incomparáveis de uma vagamente definida estrutura nacional e um ainda mais vago espírito japonês (p.143).
\end{abstract}

Funakoshi, que viveu a transição do imaginário do xogunato para a era da restauração Meiji, sofreu intensamente as influências desses arranjos imaginários, a partir dos quais as

\footnotetext{
${ }^{11}$ Autocontrole para concentrar energia e produzir maior letalidade.

${ }^{12}$ Autocontrole para modular a energia visando reduzir a letalidade do golpe e preservar a integridade física do outro.

${ }^{13} \mathrm{O}$ termo bujutsu identifica as artes marciais no Japão da era do xogunato (era medieval) (RATTI, 2006, p.23).

${ }^{14}$ Yamato Damashi - espírito Japonês.
} 
dimensões políticas e culturais do "novo Japão" se mesclaram para produzir uma nova ordem de sentidos.

Seu mérito, no entanto, é inegável. Em que pesem os deslizamentos semânticos, o caminho construído por ele viabilizou a continuidade de uma tradição milenar permitindo que "o espírito do bushi caminhe inquieto nos escuros cantinhos da alma japonesa" (RATTI, 2006, p.35).

Funakoshi constrói uma tecitura que não só define a consistência da trama entre o social e o político-cultural como também confere um novo sentido à prática do karatê.

A figura do samurai simbólico, inscrustrada como substrato da ética do bushido na concepção de Funakoshi, materializa não só o exercício da honra que lhe era inerente, mas, sobretudo, um projeto de governo. Esse fenômeno nos dá uma noção da complexidade do imaginário social cuja dinâmica serve de estofo à produção de novos significados. Consoante FERREIRA (2003), o imaginário

não é reflexo da realidade; é seu fragmento (...), ele institui histórica e culturalmente o conjunto das interpretações, das experiências individuais, vividas e construídas coletivamente. Diferentemente das representações sociais, que se originam dos dados da realidade e produzem conceitos, o imaginário ancora-se no inconsciente (...), caminha no mundo das crenças e se expressa por imagens e por discursos que pretendem configurar uma realidade (p. 23).

Assim, a ação "preservadora" de Funakoshi provocou uma cisão tão intensa entre a figura do samurai real e sua ética que abriu caminhos para a ética tornar-se, talvez, mais relevante que a proficiencia técnica. Thanatos perde seu lugar de honra e a ética tende também a perder seu caráter de univocidade, de imperativo, abrindo caminhos para a proliferação de éticas mitigadas.

\section{REFERÊNCIAS}

BARREIRA, Cristiano Roque Antunes; MASSIMI, Marina. As Ideias Psicopedagógicas e a Espiritualidade no Karatê-Do segundo a Obra de Gichin Funakoshi. Revista Psicologia: Reflexão e Crítica. v.16, n.2, 2003.

BRACHT, Valter. Sociologia crítica do esporte : uma introdução. 3.ed. — Ijuí: Ed. Unijuí, 2005.

CERTEAU, Michel. A invenção do Cotidiano. Vozes: Petrópolis, RJ, 1994.

COELHO, Milton de Souza et al. O oriente de Funakoshi no horizonte do karatê desportivizado. Revista Kinesis, Vol. 34, n. 2, p. 85-103, 2016 a.

COELHO, Milton de Souza et al. O samurai como metáfora da sociedade japonesa. Revista

Kinesis, Vol. 34, edição especial, p. 83-101, 2016 b. 
DEZEM, Rogério. Matizes do "Amarelo": A Gênese dos discursos sobre os orientais no Brasil1878-1908. São Paulo, SP Associação Editorial Humanitas, 2005.

DHOQUOIS, Regine. A Polidez Virtude das Aparências. Porto Alegre: L\&PM, 1993.

DUCROT, Oswald. Princípios de Semântica Linguística. São Paulo: Cultrix, 1972.

EAGLETON, Terry. A Ideologia da Estética. Rio de Janeiro: Jorge Zahar, 1993.

ELIAS, Norbert. O processo civilizador: uma história dos costumes. Rio de Janeiro: Zahar, 1939.

FERREIRA, Nilda Teves. Esporte, jogo imaginário social. Rio de Janeiro: Shape, 2003.

FOUCAULT, Michel. A Ordem do discurso. São Paulo: Loyola, 1996.

FUNAKOSHI, Gichin. Os vinte princípios fundamentais do Karatê: o legado espiritual do mestre. São Paulo: Cultrix, 1998.

HOBSBAWM, Eric; TERENCE, Ranger. A Invenção das tradições. 5 ed. Trad. Celina Cardim Cavalcante. Rio de Janeiro: Paz e Terra, 2008.

MAFFESOLI, Michel. O tempo das tribos. Rio de Janeiro, Forense-Universitária, 2006.

ORLANDI, Eni. (Org.). Discurso fundador. Campinas: Pontes, 1993.

PÊCHEUX, Michel. Semântica e discurso: uma crítica à afirmação do óbvio. Tradução Eni Orlandi. Campinas, SP: Editora da UNICAMP, 1988.

RATTI, Oscar. Segredos dos Samurais: As Artes marciais do Japão Feudal. In RATTI, Oscar; WESTBROOK, Adelle. Tradução de Cristina Mendes Rodrigues. São Paulo: Madras, 2006.

SAKURAI, Célia. Os Japoneses. São Paulo: Contexto, 2007.

TABORDA DE OLIVEIRA, Marcus Aurélio; OLIVEIRA, Luciane Paiva Alves; VAZ, Alexandre Fernandez. Sobre corporalidade e escolarização: contribuições para a reorientação das práticas escolares da disciplina educação física. Revista Pensar a Prática, Vol.11, n. 3, p. 303-318, 2008.

VAGO, Tarcísio. Esporte da escola, esporte na escola: da negação radical à tensão permanente um diálogo com Valter Bracht. Revista Movimento, Porto Alegre, Vol. 3, n. 5, p. 4-17, 1996.

YUZAN, Daidoji. Bushido: o código de honra do Samurai. São Paulo: Madras, 2003. 


\section{NOTAS DE AUTOR}

\section{LICENÇA DE USO}

Os autores cedem à Motrivivência - ISSN 2175-8042 os direitos exclusivos de primeira publicação, com o trabalho simultaneamente licenciado sob a Licença Creative Commons Attribution Non-Comercial ShareAlike (CC BY-NC SA) 4.0 International. Estra licença permite que terceiros remixem, adaptem e criem a partir do trabalho publicado, desde que para fins não comerciais, atribuindo o devido crédito de autoria e publicação inicial neste periódico desde que adotem a mesma licença, compartilhar igual. Os autores têm autorização para assumir contratos adicionais separadamente, para distribuição não exclusiva da versão do trabalho publicada neste periódico (ex.: publicar em repositório institucional, em site pessoal, publicar uma tradução, ou como capítulo de livro), com reconhecimento de autoria e publicação inicial neste periódico, desde que para fins não comerciais e compartilhar com a mesma licença.

\section{PUBLISHER}

Universidade Federal de Santa Catarina. Programa de Pós-Graduação em Educação Física. LaboMídia - Laboratório e Observatório da Mídia Esportiva. Publicado no Portal de Periódicos

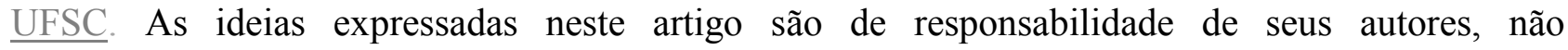
representando, necessariamente, a opinião dos editores ou da universidade.

\section{EDITORES}

Mauricio Roberto da Silva, Giovani de Lorenzi Pires, Rogério Santos Pereira.

\section{HISTÓRICO}

Recebido em: Novembro/2017

Aprovado em: Abril/2018 